\title{
A model for scour around bridge piers caused by flood waves
}

\author{
O. Link, A. Pizarro, C. Castillo \\ University of Concepción, Edmundo Larenas 215, Concepción, Chile
}

B. Ettmer

Magdeburg University of Applied Sciences, Breitscheidstraße 2, 39104 Magdeburg, Germany

S. Manfreda

University of Basilicata, Via dell'Ateneo Lucano 10, 85100 Potenza, Italy

\begin{abstract}
The local scour process during flood waves is modeled introducing the idea of an effective work by the flow on the sediment bed around the pier. Dimensional considerations show different possible formulations for the dimensionless effective flow work $W^{*}$ that, in each case, is shown to be a generalization of the flow intensity concept, commonly used in existing scour formulas. A novel experimental installation able to reproduce any hydrograph with high precision in the laboratory flume is used to carry out steady and unsteady flow experiments in order to calibrate and validate the mathematical model. Results confirm the uniqueness of the relationship between the dimensionless, effective flow work $W^{*}$ and the relative scour depth $Z^{*}$, highlighting the high predictive capacity of scour depth caused by any hydrograph. The proposed model provides good performances allowing a straightforward prediction of maximum scour depth and its evolution.
\end{abstract}

\section{INTRODUCTION}

Bridge pier scour occurs mostly during flood waves, which in medium and small sized rivers (annual mean discharge $<1000 \mathrm{~m}^{3} / \mathrm{s}$ ) have durations in the order of hours or days, which is typically shorter than the required time needed to develop the equilibrium scour, which in sands is in the order of weeks. Most existing scour formulas assume a "worst condition", considering the peak discharge of an extreme event (typically a 100-yr flood), as a constant discharge acting for an infinite time on the streambed. On the one side, this approach tends to give an overestimation of scour; on the other side this approach overlooks the possibility that smaller but longer lasting discharges produce more scour than the extreme peak discharge acting for a short time. Estimation of scour caused by flood waves is not a straightforward process. Existent formulations are scarce and their solution is iterative due to the strong dependence of actual scour rate from antecedent scour depth.

In this study, the concept of an effective flow work (Bagnold 1966, Lai et al. 2009) for scour depth prediction is adopted. Following dimensional analysis, different possible formulations for the dimensionless flow work are obtained. A novel installation able to reproduce any hydrograph with high precision in laboratory flumes is presented, in order to verify the hypothesis and select the best performing alternative for the flow work formulation.

\section{THE PROPOSED MODEL}

\subsection{Dimensional considerations}

Scour depth at a cylindrical bridge pier depends on variables characterizing the fluid, flow, sediment, and pier. In functional form:

$$
f\left(\mu, \rho, u, h, g, d_{s}, \rho_{s}, \sigma, D, t, z\right)=0
$$

where $\mu=$ dynamic fluid viscosity; $\rho=$ fluid density; $u=$ section averaged flow velocity; $h=$ flow depth; $g=$ gravitational acceleration; $d_{s}=$ representative sediment particle diameter; $\rho_{s}=$ density of sediments particles; $\sigma=$ standard deviation of the sediment particle sizes; $D=$ pier diameter; $t=$ time; and $z=$ scour depth. Eq. (1) constitutes the basis of most existent scour formulas.

Performing a dimensional analysis on Eq. (1), the following dimensionless relationship can be obtained:

$$
f\left(D^{*}, \rho^{\prime}, \sigma, \frac{u^{2}}{\rho^{\prime} g d_{s}}, \frac{h}{d_{s}}, \frac{D}{d_{s}}, \frac{u t}{d_{s}}, \frac{z}{d_{s}}\right)=0
$$

where $D^{*}=\left(\left(\rho^{\prime} g\right) / v^{2}\right)^{1 / 3} d_{s}$ denotes the dimensionless sediment particle diameter; $v=$ kinematic viscosity; $\rho^{\prime}=$ relative particle density. Both Eq. (1) and Eq. (2) are valid only under steady state. 
The challenge of the present research is to identify formulations able to interpret the time-dependence of scour from a non-stationary process of flood. In this frame, Pizarro (2015) defined the effective dimensionless flow work at a cylinder as:

$$
W^{*}=\int_{0}^{t_{e n d}} \frac{1}{t_{R}}\left(\frac{u(t)-0.5 u_{c}}{u_{R}}\right)^{3} \delta d t
$$

where $t_{\text {end }}=$ hydrograph duration, $t_{R}=$ a reference time; $u_{R}=$ a reference velocity; $u(t)=$ timedependent section averaged flow velocity; $u_{c}=$ critical velocity for incipient motion of sediment particles. For practical purposes, it is assumed that scour occurs when $u(t) \geq 0.5 u_{c}$, thus:

$\delta= \begin{cases}0 & u(t) / u_{c}<0.5 \\ 1 & u(t) / u_{c} \geq 0.5\end{cases}$

The dimensionless flow work represents a generalization of the flow intensity concept $\left(u / u_{c}\right)$ to the unsteady case. Using such concept, Eq. (2) can be written as:

$$
Z^{*}=f\left(D^{*}, \rho^{\prime}, \sigma, \frac{h}{d_{s}}, \frac{D}{d_{s}}, W^{*}\right)
$$

where $Z^{*}=$ dimensionless scour depth $\left(=z / z_{R}\right)$ and $z_{R}=$ a reference length.

Two alternatives are analyzed for the reference values involved in $Z^{*}$ and $W^{*}$ :

1) Classical approach: Assuming that the reference length, time and velocity correspond to pier diameter, equilibrium time and critical velocity, respectively. The dimensionless flow work assumes the following form:

$$
\begin{aligned}
& W^{*}\left(t_{\text {end }}\right)=\int_{0}^{t_{\text {end }}} \frac{1}{t_{\text {eq }}}\left(\frac{u(t)}{u_{c}}-0.5\right)^{3} \delta d t \\
& Z^{*}=\frac{z}{D}
\end{aligned}
$$

2) New approach: Adopting the mass conservation law for the estimation of the reference time and reference length and using the characteristic time concept $\left(t_{c}\right)$ for the pier local scour introduced by Guo (2014),

$t_{c}=\frac{D^{2}}{d_{s}\left(2 u-u_{c}\right)}$

a new formulation for the dimensionless flow work is derived.

Note that Equation (8) can be written using the same argument of the dimensionless effective flow work $W^{*}$, i.e.:

$$
t_{c}=\frac{D^{2}}{d_{s}\left(2 u(t)-u_{c}\right)}=\frac{D^{2}}{2 d_{s} u_{R}\left(\frac{u(t)-0.5 u_{c}}{u_{R}}\right)}=
$$

$$
\ldots=\frac{z_{R}}{u_{R}\left(\frac{u(t)}{u_{R}}-0.5\right)}=\frac{t_{R}^{*}}{\left(\frac{u(t)}{u_{R}}-0.5\right)}
$$

where $z_{R}=D^{2} /\left(2 d_{s}\right)$ denotes the reference length and $t_{R}{ }^{*}=z_{R} / u_{R}$ is the new reference time. The reference velocity is taken as the proposed by Oliveto \& Hager (2002), i.e.: $u_{R}=\left(\rho^{\prime} g d_{s}\right)^{0.5}$. Thus the dimensionless effective flow work $W^{*}$ and the dimensionless scour depth $Z^{*}$ become:

$$
\begin{aligned}
& W^{*}\left(t_{\text {end }}\right)=\int_{0}^{t_{\text {end }}} \frac{1}{t_{c}}\left(\frac{u(t)-0.5 u_{c}}{u_{R}}\right)^{3} \delta d t=\ldots \\
& \ldots=\int_{0}^{t_{\text {end }}} \frac{1}{t_{R}^{*}}\left(\frac{u(t)-0.5 u_{c}}{u_{R}}\right)^{4} \delta d t \\
& Z^{*}=\frac{z}{z_{R}}
\end{aligned}
$$

\subsection{Time-dependent scour depth and scour rate}

The dimensionless flow work can be used to derive an empirical formulation describing the scour depth as function of time. In this context, based on the empirical results by Franzetti et al. (1982), it is suggest the following relationship between the dimensionless scour depth and effective flow work:

$$
Z^{*}=c_{1}\left(1-e^{-c_{2} W^{* c_{3}}}\right)
$$

where $c_{1}, c_{2}$ and $c_{3}$ are fitting coefficients.

Using the above, it is possible to derive the scour rate $\left(V_{s}\right)$, defined as the variation of $Z^{*}$ in time $(t)$ :

$$
\mathrm{V}_{\mathrm{s}}=\frac{\partial \mathrm{Z}^{*}(t)}{\partial \mathrm{t}}
$$

\section{EXPERIMENTAL SET-UP}

Experiments were conducted within an in-floor rectangular flume of $26 \mathrm{~m}$ long, $1.4 \mathrm{~m}$ wide and $0.74 \mathrm{~m}$ deep at the Laboratory of Hydraulic Engineering, University of Concepción, Chile. A Plexiglas cylinder with a diameter $D=0.15 \mathrm{~m}$ was mounted in the middle of a sediment-recess located $20 \mathrm{~m}$ downstream of the flume entrance. The sediment-recess had a length of $2 \mathrm{~m}$, a width of $1.4 \mathrm{~m}$ and a depth of $0.3 \mathrm{~m}$. 


\subsection{Measuring techniques}

The scour-hole radius was measured with an accuracy of $\pm 0.4 \mathrm{~mm}$ using a laser distance sensor (LDS) located inside the Plexiglas cylinder and aligned in horizontal and radial direction, so that no refraction on the cylinder wall was observed. The sensor was driven in the vertical direction by a step-motor with a precision of $\pm 1 / 50 \mathrm{~mm}$. In the azimuthal direction, the vertical positioning system was driven by a second step-motor with an accuracy of $\pm 1 / 100^{\circ}$. That allowed the turnaround view of the distance sensor in the scour-hole, taking various vertical profiles in different azimuthal half-planes for determination of the azimuthal half-plane where maximum scour depth occurred. The measured radius, vertical coordinate, and the azimuthal coordinate of the sensor position were registered with a frequency of $70 \mathrm{~Hz}$. Scour rate, maximum scour depth in time, and final scour depth were computed in order to verify the proposed model.

Discharge was controlled with a closed loop control system, taking the measured discharge and flow depth as outputs. Corrections to account for differences between specified and measured discharges were made on the frequency of the pump motor, based on a Proportional-Integral (PI) controller (Åström \& Hägglund 1995) set up by means of a programmable logic controller (PLC) and a variablefrequency drive (VFD), as schematized in Figure 1. Flow depth was controlled by adjusting the tail gate at the end of the flume, and was measured with ultrasonic distance sensors (UDS) placed along the flume. The discharge $Q_{\text {measured }}$ was measured with an orifice plate device installed in the recirculation system with a precision of $\pm 1 \%$.

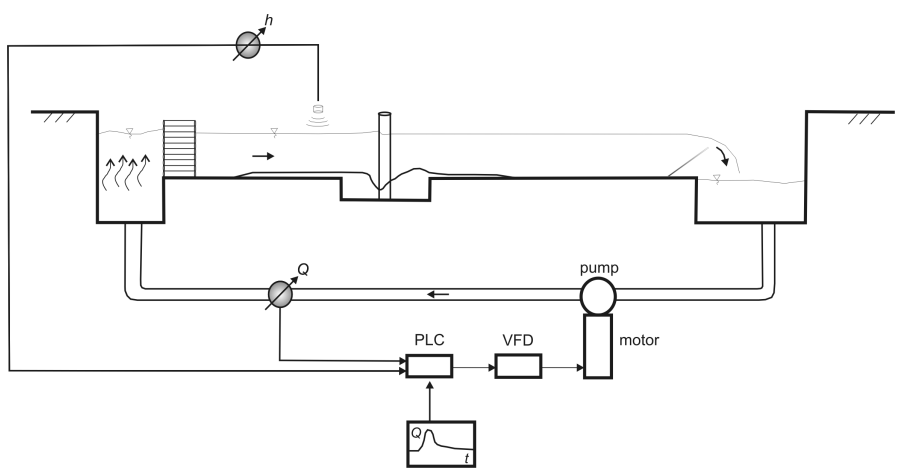

Figure 1. Schematic view of the experimental installation.

\subsection{Bed material}

In the experiments, fine sand was used as bed material. The dimensionless particle diameter $D^{*}=9$, the relative density $\rho^{\prime}=1.65$, and the standard deviation of the sediment grain sizes $\sigma=1.45$. The critical velocity for the incipient motion of the sediment particles $u_{c}$ was experimentally determined in prelimi- nary runs. Table 1 summarizes the properties of the bed material.

Table 1. Properties of the bed material.

\begin{tabular}{|c|c|c|c|c|}
\hline \multirow[t]{2}{*}{ Property } & $\rho_{s}$ & $d_{50}$ & $\sigma$ & $u_{c}$ \\
\hline & $\mathrm{kg} / \mathrm{m}^{3}$ & $\mathrm{~mm}$ & - & $\mathrm{m} / \mathrm{s}$ \\
\hline Quantity & 2650 & 0.36 & 1.45 & 0.32 \\
\hline
\end{tabular}

\subsection{Hydraulic conditions and experimental series}

Experiments on scour were conducted with constant discharges until equilibrium and with hydrographs having different duration, and shapes. Maximum discharge during an experiment corresponded to $95 \%$ of Shields critical condition for the initiation of motion of the sand particles at the undisturbed plane bed. Thus, the runs corresponded to clear water conditions. A base flow of $35 \mathrm{l} / \mathrm{s}$ and a section averaged flow depth of $h=1.4 \mathrm{D}=0.21 \mathrm{~m}$, corresponding to a flow intensity of 0.37 , were imposed as initial condition. A total of three experimental series are analyzed: Series A included two scour experiments with constant discharge with the aim of exploring the relationship between $W^{*}$ and $Z^{*}$ until equilibrium, with different flow intensities $\left(\mathrm{A}-1: \mathrm{u} / \mathrm{u}_{\mathrm{c}}=0.91 / \mathrm{A}-2\right.$ : $\left.\mathrm{u} / \mathrm{u}_{\mathrm{c}}=0.76\right)$. Series B included two scour experiments with short duration, i.e. high flow acceleration, and triangular and sinusoidal shapes, respectively. Series C included three scour experiments with longer duration than Series B: Step-wise and sinusoidal hydrographs were produced. Figure 2 shows the hydrographs corresponding to each experiment and Table 2 summarizes the hydraulic conditions for the experiments.

Table 2. Hydraulic conditions for the experiments.

\begin{tabular}{|c|c|c|c|c|c|}
\hline \multirow[t]{2}{*}{ No. } & $u_{p^{*}}$ & $h_{p} *$ & $t_{p^{*}}$ & $t_{\text {end }}$ & $u_{p} * / u_{c}$ \\
\hline & $\mathrm{m} / \mathrm{s}$ & $\mathrm{m}$ & $\min$ & $\min$ & - \\
\hline A-1 & 0.29 & 0.22 & N/A & 6400 & 0.91 \\
\hline A-2 & 0.24 & 0.23 & N/A & 8600 & 0.76 \\
\hline B-1 & 0.28 & 0.23 & 12.75 & 25.5 & 0.87 \\
\hline B-2 & 0.28 & 0.23 & 3.3 & 20 & 0.87 \\
\hline C-1 & 0.29 & 0.22 & 20 & 120 & 0.91 \\
\hline C-2 & 0.29 & 0.22 & 100 & 120 & 0.91 \\
\hline C-3 & 0.29 & 0.22 & 40 & 90 & 0.91 \\
\hline
\end{tabular}

* Subscript "p" denotes peak condition.

Note that for all experiments $D^{*}=9 ; \rho^{\prime}=1.65$; $\sigma=1.45 ; h_{p} / d_{s} \approx 610 ;$ and $D / d_{s}=416.67$. Thus the functional relationship presented in Eq. (5) can be simplified to:

$$
Z^{*}=f\left(W^{*}\right) \text {. }
$$




\section{RESULTS}

The experimental installation reproduced the desired hydrographs very well, with standard errors less than $1.21 \mathrm{l} / \mathrm{s}$, i.e less than $1.7 \%$, confirming that the flow control scheme is adequate for applications in fluvial hydraulics.
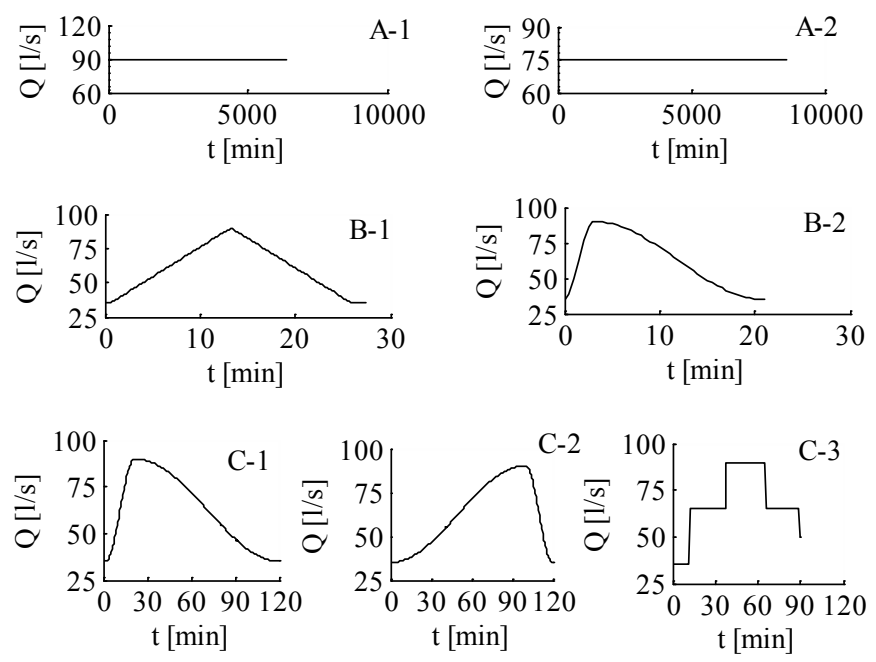

Figure 2. Hydrographs of the experimental series.

\subsection{Steady flow}

The functional relationship between dimensionless scour depth $Z^{*}$, and dimensionless flow work $W^{*}$ is explored using the two different formulations of the dimensionless flow work (Eq. 6 vs Eq. 10b). Such comparison was possible using experiments carried out under steady-state conditions (Series A). Figure 3 shows the dimensionless scour depth on dimensionless flow work for the two experiments of Series A, according to the two alternative formulations of the reference values examined herein.

All formulations of the reference values proposed show the same tendency, increasing $Z^{*}$ with $W^{*}$. For the new approach measured values clearly collapse into one single curve, demonstrating that the relation between $Z^{*}$ and $W^{*}$ is unique. Thus, in the following, the reference variables are adopted according to the new approach.

Using the formulation proposed in Eq. (12), it was possible to calibrate the coefficients $c_{1}, c_{2}$ and $c_{3}$ that have been determined using the Matlab nonlinear curve-fit function. The values of the coefficients are $c_{1}=0.0075, c_{2}=0.097$, and $c_{3}=0.38$. The determination coefficient obtained is $r^{2}=0.99$.

\subsection{Time-dependent scour depth}

In the following the proposed model is adopted under unsteady conditions. In particular, Figure 4 shows that hydrograph shapes affected the evolution of scour depth in time, but not its final value. Com- parison of final scour depth in experiments B-1 and $\mathrm{B}-2$, as well as in C-1, C-2 and C-3 confirm that the relation between the dimensionless, effective flow work and scour depth is unique (same final $W^{*}$ value produces the same $Z^{*}$ value).
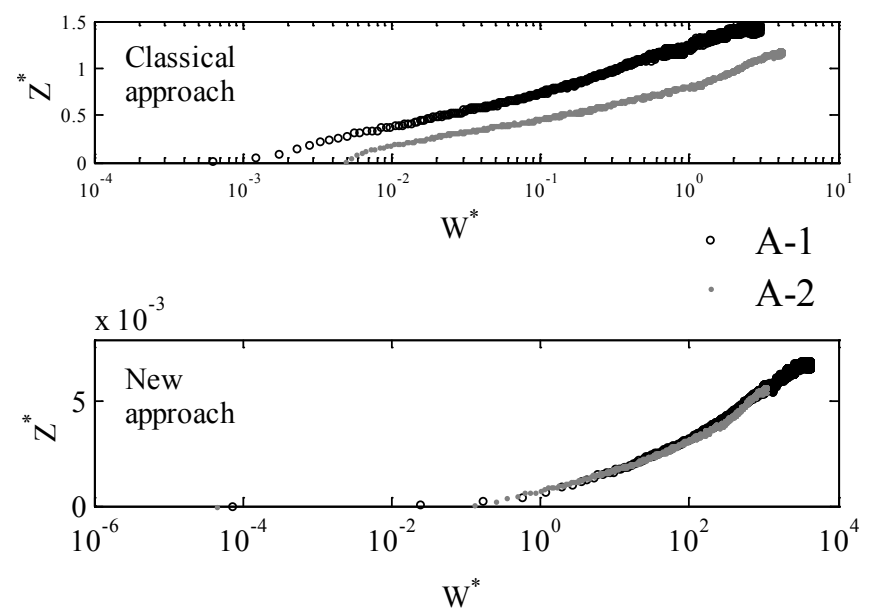

Figure 3. Evolution of $Z^{*}$ on $W^{*}$ for Series A.

\subsection{Comparison with literature}

Scarce data have been published in the literature to test the model proposed in Eq. (12) for prediction of scour under flood waves.

In this article, the experimental data by López et al. (2014), reported Table 3, is used. López et al. 's (2014) measurements need to be rescaled because of the differences in their experimental setup. These dissimilarities are due to dimensionless sediment particle diameter (In the present study $D^{*}=9$, while in López et al. 's (2014) experiments $\left.D^{*}=41.5\right)$ and relative roughness (In the present study $D / d_{s}=$ 416.67, while in López et al. 's (2014) experiments $\left.D / d_{s}=54.55\right)$. In order to take scale effects due to differences in relative roughness into account, the predictions of Eq. (12) were corrected using the formulation proposed by Lee \& Sturm (2009).

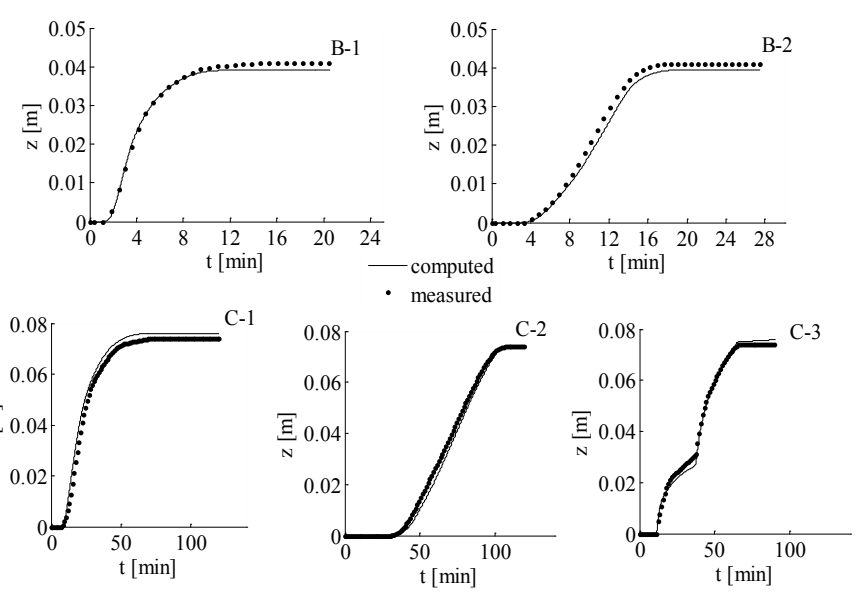

Figure 4. Scour depth in time for Series B and C. 
Table 3. López et al. (2014) data employed in the present study.

\begin{tabular}{|c|c|c|c|c|}
\hline \multirow[t]{2}{*}{ Run } & $Q_{p^{*}}$ & $h_{p^{*}}$ & $u_{p^{*}} / u_{c}$ & $z$ \\
\hline & $1 / \mathrm{s}$ & $\mathrm{cm}$ & - & $\mathrm{cm}$ \\
\hline U1a & 69.2 & 20.4 & 0.82 & 12.51 \\
\hline U1b & 70.1 & 20.1 & 0.85 & 12.34 \\
\hline U1c & 68.8 & 20.0 & 0.84 & 12.08 \\
\hline $\mathrm{U} 2 \mathrm{a}$ & 69.7 & 20.0 & 0.85 & 11.31 \\
\hline $\mathrm{U} 2 \mathrm{~b}$ & 69.8 & 20.1 & 0.85 & 11.16 \\
\hline U3 & 69.4 & 19.8 & 0.85 & 13.19 \\
\hline U4 & 70.2 & 20.1 & 0.85 & 10.74 \\
\hline U5 & 54.3 & 18.3 & 0.73 & 7.73 \\
\hline U6 & 54.0 & 18.2 & 0.73 & 7.41 \\
\hline U7 & 54.6 & 18.1 & 0.74 & 11.30 \\
\hline
\end{tabular}

* Subscript "p" denotes peak condition.

Figure 5 shows the comparison between the experimental results by López et al. (2014) and scour depth computed with the corrected Eq. (12). Except run U3, all experiments by López et al. (2014) are properly interpreted by the proposed model with errors less than $25 \%$. Differences between the two studies are attributable to viscous effects $\left(D^{*}\right)$.

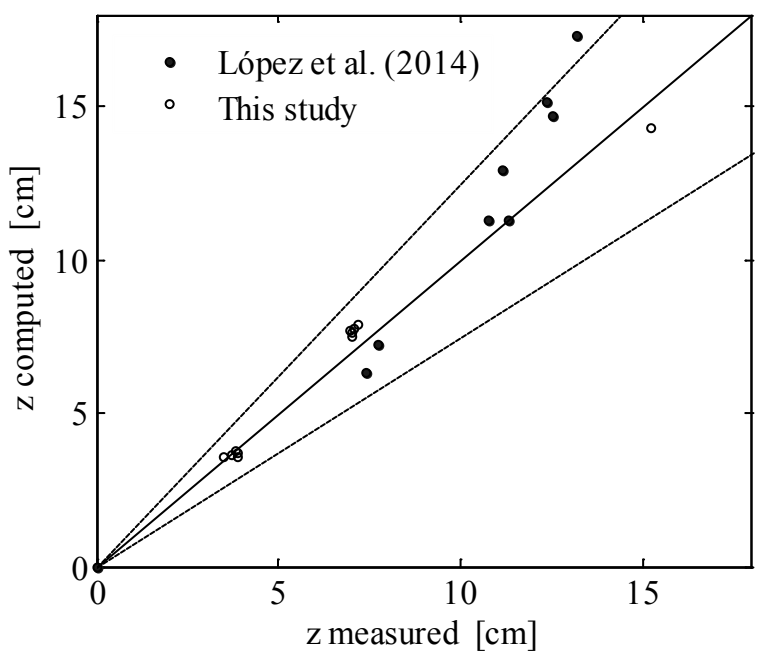

Figure 5. Comparison with literature data.

\section{CONCLUSIONS}

The pier scour caused by several different flood hydrographs was analyzed introducing the idea of an effective work by the flow on the sediment bed around the pier. Different possible formulations for the dimensionless flow work and the corresponding dimensionless parameters that govern scouring were tested with laboratory experiments conducted in a novel installation able to reproduce any hydrograph with high precision in a flume.
The results highlighted that the effective dimensionless work $W^{*}$ has a high predictive capacity of scour caused by any hydrograph, as the relation between the effective dimensionless work and the dimensionless scour depth is unique. In particular, the proposed model provides a good performance allowing for a straightforward prediction of maximum scour depth.

The presented experiments represent a first step in the study of the interaction of more complex flood hydrographs with fluvial structures. In the future, we plan to explore: (1) Hydrographs with multiple peaks and shapes closer to reality for testing the effects of flow acceleration on scour depth; (2) The role of sediment properties on scour, as well as the scour behavior under flood waves with significantly higher flow velocities to improve the understanding regarding the reliability of the proposed formulation.

\section{ACKNOWLEDGEMENTS}

Presented results are part of the research project Fondecyt 1150997. Financial support by Red Doctoral REDOC.CTA and by CRHIAM Fondap-Center 15130015 is greatly acknowledged. Academic exchange was possible through the financial support of the German academic exchange service DAAD, the Chilean research council CONICYT through grant PCCI12027, and the Erasmus Mundus project Elarch Grant Nr. 552129-EM-1-2014-1-IT-ERA MUNDUS-EMA21.

\section{REFERENCES}

Åström, K. J. \& Hägglund, T. (1995). New tuning methods for PID controllers. In Proceedings of the 3rd European Control Conference: 2456-62.

Bagnold, R. (1966). An approach to the sediment transport problem from general physics. U.S. Geological Survey Professional Paper. 422-J.

Franzetti, S., Larcan, E., and Mignosa, P. (1982). Influence of scour tests duration on the evaluation of ultimate scour around circular piers. Proceedings of the International Conference on Hydraulic Modeling of Civil Engineering Structures, Coventry, UK: 381-396.

Guo, J. (2014). Semi-analytical Model for Temporal Clearwater Scour at Prototype Piers. Journal of. Hydraulic Research. 52(3): 366-374.

Lai, J., Chang, W., and Yen, C. (2009). Maximum Local Scour Depth at Bridge Piers under Unsteady Flow. Journal of Hydraulic Engineering. 135(7): 609-614.

Lee, S. \& Sturm, T. (2009). Effect of Sediment Size Scaling on Physical Modeling of Bridge Pier Scour. Journal of Hydraulic Engineering. 135(10): 793-802.

López, G., Teixeira, L., Ortega-Sánchez, M., and Simarro, G. (2014). Estimating Final Scour Depth under Clear-Water Flood Waves. Journal of Hydraulic Engineering. 140(3): 328-332. 
Oliveto, G., and Hager, W. (2002). Temporal Evolution of Clear-water Pier and Abutment Scour. Journal of Hydraulic Engineering. 128(9): 811-820.

Pizarro, A. (2015). Effective flow work for estimation of pier scour under flood waves. Dissertation for the Master degree of Civil Engineer. University of Concepción, Concepción, Chile. 